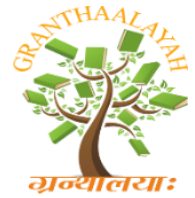

\author{
INTERNATIONAL JOURNAL OF RE
GRANTHAALAYAH \\ A knowledge Repository
}

Science

\title{
BENEFITS AND DIFFICULTIES OF OBSTETRIC PSYCHOPROPHYLAXIS IN PREGNANT WOMEN, GUAYAS -ECUADOR
}

\author{
Obsta Vicky Narea Morales MSc ${ }^{1}$, Dr. Jorge Daher Nader MSc ${ }^{2}$, Obsta. Katherine \\ Rodriguez $^{3}$, Obsta. Yesica Pazmiño Mera MSc ${ }^{4}$, Obsta. Cecilia Herrera Martínez MSc ${ }^{5}$ \\ 1,2,3,4,5 Teachers of The Career of Obstetrics of The Faculty of Medical Sciences of The \\ University of Guayaquil-Ecuador
}

\begin{abstract}
The objective of this research work was to determine the benefits and difficulties of obstetric psychoprophylaxis in pregnant women of the Cerecita Health Center, Guayas - Ecuador from January - December 2017. The study design is non-experimental, cases and controls, retrospective, in the The research methodology used the data collection form and an ad hoc form was prepared. To carry out the investigation, an application was submitted to the director of the health center. The sample consisted of 80 nulliparous and multiparous pregnant women, who met the inclusion and exclusion criteria. The following results were obtained: that if there are significant benefits with pregnant women who attended the psychoprophylaxis sessions; With an adequate assistance of pregnant women, $70 \%$ completed all the sessions of Psychoprophylaxis, with a time of less than 6 hours of the dilation period of $46.43 \%$; With an expulsion period of less than 25 minutes in $76.79 \%$ More eutocic deliveries in $82.14 \%$ of the pregnant women who completed the PPO sessions, $78.57 \%$ of the cases did not require medication in the dilation phase; Apgar at the minute, greater than 8 in $96.43 \%$, and at 5 minutes in $98.21 \%$. Only $1.78 \%$ of the newborns of the mothers in the case group had apnea and in fetuses of $3500 \mathrm{gms}$ or more, the $40 \%$ had an expulsive no greater than 25 minutes. The benefits observed in the present study, on labor, on the newborn, was a better Apgar at the first minute of life $(\mathrm{p}=0.091 \times 10-4, \mathrm{OR}=9)$.
\end{abstract}

Keywords: Psychoprophylaxis-Obstetrics; Pregnant; Benefits; Difficulties.

Cite This Article: Obsta Vicky Narea Morales MSc, Dr. Jorge Daher Nader MSc, Obsta. Katherine Rodriguez, Obsta. Yesica Pazmiño Mera MSc, and Obsta. Cecilia Herrera Martínez MSc. (2020). "BENEFITS AND DIFFICULTIES OF OBSTETRIC PSYCHOPROPHYLAXIS IN PREGNANT WOMEN, GUAYAS -ECUADOR.” International Journal of Research - Granthaalayah, 8(2), 14-18. https://doi.org/10.29121/granthaalayah.v8.i2.2020.176.

\section{Introduction}

Obstetric Psychoprophylaxis is a technique to prepare the pregnant woman and her partner, in an integral, physical, cognitive and psychological way, through educational activities, neuromuscular relaxation techniques, exercises, analgic positions and prenatal stimulation, according to their 
obstetric conditions, to achieve in the pregnant women knowledge, attitudes and healthy practices, that allow their effective participation with tranquility and security during pregnancy, childbirth, postpartum and lactation, in this way, improve their quality of life and general and obstetric conditions. In 2014, the technical standard of obstetric psychoprophylaxis and prenatal stimulation of the Ministry of Public Health was implemented in Ecuador. Its general objective is to strengthen the Health System with a document that guides the actions that must be carried out in the health units to provide obstetric psychoprophylaxis and Prenatal Stimulation to pregnant women, as part of their comprehensive care, with a family, community and intercultural approach, contributing to the reduction of maternal and perinatal morbidity and mortality in Ecuador.

\section{Materials and Methods}

It is a descriptive, analytical study, it is not experimental, comparative, control case, retrospective. The population is made up of 9,600 people among men, women and children in the Cerecita enclosure of the province of Guayas - Ecuador, from which a sample consisting of 80 nulliparous and multiparous pregnant women who attended obstetric Psychoprophylaxis sessions that complied with the Inclusion and exclusion criteria.

In the inclusion criteria, pregnant women whose delivery is eutocic, single fetus, all presentations, pregnant women who attended obstetric psychoprophylaxis sessions are included. In the exclusion criteria, pregnant women whose delivery will be caesarean section, multiple pregnancy, pregnant women with high-risk pregnancy are excluded.

\section{Results}

Table 1: Benefits obtained by pregnant women who perform obstetric psychoprophylaxis sessions during pregnancy.

\begin{tabular}{|l|cr|ll|}
\hline Mother variables & \multicolumn{2}{|c|}{ Six Sessions Ppo } & \multicolumn{2}{c|}{ Sessions Ppo } \\
& Si (56) & No (24) & N & \% \\
\hline Complete dilation up to 6 Hours & 20 & 35.714 & 5 & 20.83 \\
\hline No use of medications & 44 & 78.57 & 12 & 50 \\
\hline Expulsion less than 25' & 43 & 76.79 & 10 & 41.67 \\
\hline Eutocic birth & 46 & 82.14 & 11 & 45.83 \\
\hline Clear amniotic liquid & 55 & 98.21 & 23 & 95.83 \\
\hline
\end{tabular}

Table 2: Benefits obtained by newborns from mothers who receive six or more sessions of obstetric psychoprophylaxis.

\begin{tabular}{|l|lr|rrr|}
\hline RN Variables & \multicolumn{2}{|c|}{ SIX SESSIONS PPO } & \multicolumn{2}{|c|}{ SESSIONS PPO } \\
& \multicolumn{2}{|c|}{ SI } & NO & \\
& N & \% & N & \% \\
\hline APGAR 1'>8 & 54 & 96,43 & 18 & 75 \\
\hline APGAR 5'>8 & 55 & 98,21 & 18 & 75 \\
\hline APNEA AT BIRTH & 1 & 1,78 & 4 & 16.67 \\
\hline $\begin{array}{l}\text { EXPULSIVE }<25{ }^{\prime} \\
\text { gramos. }\end{array}$ & EN FETO $>3500$ & 12 & 40 & 1 & 11.11 \\
\hline
\end{tabular}


Table 3: Difficulties presented by pregnant women to perform obstetric psychoprophylaxis sessions.

\begin{tabular}{|l|lc|lr|}
\hline DIFFICULTIES PPO & \multicolumn{2}{|c|}{ SIX < SESSIONS DE PPO } & \multicolumn{2}{c|}{ NO } \\
& SI & \% & N & \\
\hline No Difficulties & 32 & 57.14 & 2 & 8.33 \\
\hline Hour Inadequate & 11 & 19.64 & 20 & 83.33 \\
\hline Inadequate ambiences & 4 & 7.14 & 0 & 0.00 \\
\hline Lack of comfort & 7 & 12.50 & 0 & 0.00 \\
\hline $\begin{array}{l}\text { Lack of commitment on the part of } \\
\text { the couple. }\end{array}$ & 2 & 3.57 & 2 & 8.33 \\
\hline
\end{tabular}

\section{Discussion}

In the benefits obtained from the pregnant woman, we did obtain statistically significant differences, when comparing the two groups of pregnant women, they were:

Complete dilation in less than six hours. With an Odds Ratio of 2.11 (95\% CI 1.12 - 3.97) and a p-value of less than 0.05. This OR means that in those women who completed the six sessions of psychoprophylaxis they are 2.11 times more likely to have their dilation completed in up to six hours.

Eutocic delivery with an Odds Ratio of 6.27 (95\% CI 3.224 - 12.2) and a highly significant p value. It indicates that, if a pregnant woman has eutocic delivery, there is a 6.27 times probability that she has completed all the sessions of Obstetric Psychoprophylaxis.

Expulsive with a duration less than 25'. With an Odds Ratio of 4.63 (95\% CI 2.513 - 8.534) and a highly significant $\mathrm{p}$ value. It indicates that the pregnant woman who achieves an expulsion period of less than 25 'is 4.63 times the probability that she has completed her six sessions of Obstetric Psychoprophylaxis.

In the Benefits obtained by newborns from mothers who receive six or more sessions of obstetric psychoprophylaxis.

96.43\% (54/56) of all pregnant women who completed their PPO sessions, had their children with an Apgar per minute, optimal, between eight and ten points. The same occurs in only $75 \%$ of the control group (mothers with less than six PPO sessions). The difference of both percentages is statistically significant ( $p>0.05$ ) and an Odds Ratio of nine was obtained. That is, before a newborn with Apgar at the minute equal to or greater than 8, it is 9 times likely that his mother has had complete sessions of Obstetric Psychoprophylaxis.

98.21\% (55/56) of all pregnant women who completed their obstetric psychoprophylaxis sessions, had their children with an Apgar at five minutes, optimal, between eight and ten points. The same occurs in only $75 \%$ of the control group (mothers with less than six sessions of Obstetric Psychoprophylaxis). The difference of both percentages is statistically significant ( $>>0.05)$ and an Odds Ratio of 18.29 was obtained. That is, before a newborn with Apgar at five minutes equal 
to or greater than 8 , it is 18.29 times likely that his mother had had full sessions of Obstetric Psychoprophylaxis.

Regarding apnea at birth, we found that Obstetric Psychoprophylaxis sessions have a protective effect: in newborns who do not have apnea, there is a $99.1 \%$ probability that their mother has completed the full PPO program. The difference between the two groups evaluated is highly significant.

\section{Conclusions}

1) The benefits observed in the present study, on labor, were: shorter dilation period ( $\mathrm{p}=$ 0.016; OR 2.11); less use of medications in the period of dilation and expulsion $(\mathrm{p}=0.025$ $\mathrm{x} 10-5, \mathrm{OR}=3.64)$; shorter expulsion period $(\mathrm{p}=0.014 \mathrm{x} 10-6, \mathrm{OR}=4.63)$, higher percentage of eutocic births $(\mathrm{p}=0.01 \times 10-5 ; \mathrm{OR}=6.27)$

2) The benefit observed in the present study, on the newborn, was a better Apgar at the first minute of life $(\mathrm{p}=0.091 \times 10-4, \mathrm{OR}=9)$.

3) $42.50 \%$ of the participants (34/80), said they had no difficulties in complying with the PPO sessions, of the total number of participants who reported having some difficulty, $56.76 \%$ reported inappropriate schedules; $18.92 \%$ reported lack of comfort or convenience, $10.81 \%$ reported the lack of commitment of their partners and also $10.81 \%$.

Confidentiality: The patient's personal data will be protected by medical ethics.

Conflicts of Interest: The authors declare no conflict of interest.

\section{References}

[1] Rosales D. Effectiveness of psychoprophylaxis during pregnancy, Centro de Salud Ambato Ecuador Thesis Baccalaureate. Technical University of Ambato Ecuador 2017. 86 pp

[2] Gifted J. Psychoprophylaxis during pregnancy to improve the process and results of labor and conditions of the newborn. Comparative study in three health centers: Augusto Egas, Los Rosales and Concordia in the province of Santo Domingo de los Tsáchilas, during the period 2015. Thesis for second specialty. Pontifical Catholic University of Ecuador. Ecuador, 2017. 70 pp.

[3] Játiva M. Application of Psychoprophylaxis and its importance in natural birth in the Health Center No. 3 of Ambato. High school thesis. Technical University of Ambato. Ecuador, 2015. 192 pp.

[4] Guerrero J, Paguay C. Application of Psychoprophylaxis and its importance in natural childbirth in the Health Center No. 3 of Ambato. High school thesis. Central University of Ecuador. Ecuador, 2013. 213 pp.

[5] Barrientos S, Chapoñan C. List of pregnant women who attend the obstetric psychoprophylaxis program and the level of anxiety at Sagaro hospital - 2017. Thesis for baccalaureate degree, National University of Tumbes. Peru, 2017. 63 pp.

[6] Huete C. Relationship between attending the course of obstetric psychoprophylaxis and the risk of presenting postpartum depression in immediate postpartum care attended at the National Maternal Perinatal Institute in the period of March - April 2017. Thesis for baccalaureate degree. National University of San Marcos. Peru, 2017. 62 pp.

[7] García V. Influence of obstetric psychoprophylaxis in the prevention of maternal and neonatal complications, of deliveries attended at the Regional Hospital of Loreto, from January to December 2016. Thesis for bachelor's degree. National University of the Peruvian Amazon. Peru, 2017. 61pp. 
[8] Zorrilla G. Benefits of obstetric psychoprophylaxis in pregnant women during the labor process (active phase) and the newborn in the Manuel Barreto Maternal and Child Health Center of San Juan de Miraflores June - August 2015. Thesis for Baccalaureate. San Martin de Porres University. Peru, 2016. 60 pp.

[9] Zurita M, Benefits of Obstetric Psychoprophylaxis in pregnant women during the process of labor and the newborn, Hospital Vitarte - Lima -Perú. High school thesis. Peruvian Wings University. Peru 2015

[10] Poma R, Rojas, F. Benefits of Obstetric Psychoprophylaxis in pregnant women during the birth process and in the newborn in the C.S of Chupaca from July to December 2015. Thesis for high school. Peruvian University of the Center. Peru, 2015. 78 pp.

[11] Méndez M. Psychoprophylaxis and complications in labor (study conducted in women who attended the Center for Psycho-prophylactic Preparation of Aída Castillo de Mazariegos of the Head of Quetzaltenango). High school thesis. Rafael Landívar University. Guatemala 2015. 86 pp.

[12] Aguilar M. Perinatal results at the time of delivery of women who received the prenatal stimulation program, San Cecilio-Spain Clinical Hospital. High school thesis. University of Granada, Spain 2012. 2102-2112 pp.

[13] González J, Fernández B, Gómez J. History of labor pain relief in Spain. An Real Acad Med Cir Vall 2015; 52: 71-84.

[14] Ruiz L, González H. The use of hypnosis in the management and relief of pain during childbirth: literature review. Rev Dig of Med Psicosom and Psicoter. Vol. 4 (2014). Pp 1-18

[15] Fujihara S, Tsukisawa M. Introduction of the psychoprophylactic method and its influence on the prenatal care program for institutional parturition in Japan: the practice in the Central Hospital of Maternity of the Japanese Red Cross Society and Oomori Red Cross Hospital, 1953-1964 . Nihon Ishigaku Zasshi. 2014 Mar; 60 (1): 49-64.

[16] Fujihara S, Tsukisawa M. An Analysis of the Controversy on the Psychoprophylaxis Method in the Japanese Medical Journal "Obstetrics and Gynecology," 1954-1957. Nihon Ishigaku Zasshi. 2015 Jun; 61 (2): 131-44.

[17] Hrešanová E. The Psychoprophylactic Method of Painless Childbirth in Socialist Czechoslovakia: from State Propaganda to Activism of Enthusiasts. Med Hist. 2016 Oct; 60 (4): 534-56.

[18] Caron-Leulliez M. Childbirth without pain. Politics in France during the cold war. Can Bull Med Hist. 2006; 23 (1): 69-88.

[19] Chable-Uitz G, García-Cruz K. Advantages of perinatal psychoprophylaxis. Rev Sanid Milit Mex 2013; 67 (3) May-Jun: 106-114.

[20] Morales S, García Y, Agurto M, Benavente A. Obstetric Psychoprophylaxis and prenatal stimulation in various regions of Peru. Horiz Med Ener - Mar 2014; 14 (1): $42-48$.

[21] Ministry of Health. Technical Guide for Obstetric Psychoprophylaxis and Prenatal Stimulation. Peru. 2011. 79 pp.

[22] Official Gazette El Peruano. Law 28124. Law for the Promotion of Prenatal and Early Stimulation. Ministry of Health. Peru, 2003. Pp 257256-57.

[23] Official Gazette El Peruano. D.S.006-2006 approving the Regulations of the Law for the Promotion of Prenatal and Early Stimulation. Law No. 28124. Ministry of Health. Peru 2006. Pp 312370-77.

[24] Ministry of Public Health. Technical Standard Obstetric Psychoprophylaxis and Perinatal Stimulation. National Directorate of Regulation Quito-Ecuador 2014. 1st edition.

*Corresponding author.

E-mail address: Vicky.naream@ug.edu.ec/jorge.dahern@ug.edu.ec/Katherine.rodriguezb@ug.edu.ec/ yesica.pazminom@ug.edu.ec/cecilia.herreram@ug.edu.ec 